$\xi=-1$

\title{
Strength Properties of Reinforced Peat Using Fiber-Polyester and Shredded Rubber-Crumb as Reinforcement Material
}

\author{
Norazzlina M.Sa'don ${ }^{1 *}$, Abdul Razak Abdul Karim ${ }^{1}$, Siti Noor Linda Taib ${ }^{1}$ \& Mahshuri Yusof ${ }^{1}$ \\ ${ }^{1}$ Faculty of Engineering, Universiti Malaysia Sarawak, 94300 Kota Samarahan Sarawak, Malaysia \\ *Corresponding author E-mail: msazzlin@unimas.my
}

\begin{abstract}
This paper presents an investigation of the strength improvement of reinforced peat by using the fiber reinforcement techniques of the lightweight waste material, i.e., tire-waste disposal. The fiber-polyester and shredded rubber crumb are extracted and process for the collected tire-waste disposal. In this study, the fiber-polyester and shredded rubber-crumb are mixed with peat (Pt), with undrained shear strength, cu of $<10 \mathrm{kPa}$ and $5 \%$ cement content, which act as a binder. The peat samples are mixed at various percentages of fiberpolyester and shredded rubber-crumb. The compacted fiber-reinforced peat samples were prepared at optimum moisture content, mixes thoroughly to a uniform condition by laboratory mixer and air cured for 7 and 28 days in a single batch. The strength improvement of undrained shear strength, cu of $>100 \mathrm{kPa}$ is targeted at minimal percentages of cement added. The Unconfined Compression Strength (UCS) and California Bearing Ratio (CBR) tests are performed for determination of the engineering properties of fiber-reinforced peat. Based on the results obtained, one can be seen that both fiber-polyester and shredded rubber crumb shows an increment in unconfined compressive strength value of $214 \mathrm{kPa}$ and $55 \mathrm{kPa}$, respectively. In summary, the study shown that, the inclusion of fiber-polyester and shredded rubber-crumb from tire-waste disposal increased the effective contact area between reinforced material and peat, which then improved the strength significantly, and the used of tire-waste disposal for the construction may not only provide the alternative mean of recycling and reusing, however, it also addressed economic and environmental concerns and reduce construction cost by making the best use of locally available materials.
\end{abstract}

Keywords: Peat, fiber-reinforced, shredded rubber-crumb, polyester fiber and tire waste disposal.

\section{Introduction}

Peat is defined as a non-homogeneous deposit of partially decomposed vegetative matter saturated with water and encountered in low-lying areas where the water table is near or above the ground surface [1]. They are present mostly in surface soils, but in some cases as deep deposits. The overall hydrological characteristic depends upon the rainfall and the surface topography. High moisture content in peat is the main factor contributing to the characterization of peat with low bearing capacity and bulk density. Due to this, peat is incapable of carrying excessive weight. The consequences for engineering structures on peat resulting from the high and rapid compressibility are often very serious [2]. A study performed in Sibu town by [3] shows that the removal of water by drainage leading to the bulging of peat near roads and caused ground settlement due to their poor mechanical performance.

In Sarawak, about 90 percent of peat is classified as deep peat (depth of more than 1.5 meters). The depth of peat soil layers increases from the coast towards the inland. According to [4], field investigation conducted in Western Sarawak has proven that there are three significant layers differentiated by its level of humidification, where each layer overlain the subsequent layer. The top thin layer of $0.5 \mathrm{~m}$ to $1.5 \mathrm{~m}$ thick is recognized as Sapric peat with a fiber content of less than 33 percent. The second layer of peat, overlain by Sapric peat, is recognized as Hemic peat with fiber content ranging from 33 to 66 percent. The near beneath of peat soil layers, overlain by hemic peat, is recognized as Fibric peat with a fiber content of greater than 66 percent, and a layer of grey mangrove clay may be likely to be seen under the fibric layers. Further classification using Von Post degree of humidification, peat can be categorized into three main groups, namely Fibric (H1-H3), Hemic (H4-H6) and Sapric (H7-H10). The content of peat differs from location to location due to the factor such as origin fiber, temperature and humidity [5]. These soils are problematic, hence suitable geotechnical parameters and construction techniques needed for this type of ground condition.

In practice, the common solution when dealing with peat is to simply remove, replace and displace this problematic soil with other good materials to improve the road sub-grade and also filled embankment. However, it is quite challenging when dealing with deep peat of more than $5 \mathrm{~m}$. Improvement of certain desired properties of peat such as compaction, California Bearing Ratio (CBR), unconfined compression, shear strength, swelling characteristic can be undertaken by a variety of soil improvement techniques. There are many soil improvement techniques either chemical or mechanical types. All these require qualified manpower and equipment to ensure adequate performance [6]. Therefore, one of the alternative construction methods is using the soil stabilization/reinforcement techniques as reinforcement layer. This method is considered to be economical (inexpensive), accessible and environmentally friendly, which involves the use of waste materials such as tire-waste disposal, fly ash, quarry dust and sawdust. The main purposes of the techniques are to improve the slope stability, increase bearing capacity and also reduce settlement and lateral deformation of the peat embankment. 
Many experimental studies on the geotechnical characteristics, chemical stabilization and reinforcement technique of peat are reported in the literature. However, information about the strength effect of processed tire-waste disposal using shredded rubbercrumb and fiber-polyester as reinforcement materials for reinforced peat as sub-grade is scarce. In addition, the soil stabilization/reinforcement techniques with tire-waste disposal for construction may not only provide the alternative mean of recycling and reusing, however, it also addressed economic and environmental concerns as well as reduce the construction cost by making the best use of locally available materials.

This paper presents the findings on geotechnical characteristics and strength improvements of fiber-polyester and shredded rubber-crumb for reinforced peat with targeted undrained shear strength, $\mathrm{cu}>100 \mathrm{kPa}$. A series of laboratory testing, namely Proctor compaction test, unconfined compressive strength (UCS) tests and California bearing ratio (CBR) tests have been performed in Geotechnical Laboratory, UNIMAS. All the experimental investigations were conducted in accordance to BS1377: Part 2:1990 unless stated otherwise.

\section{Materials}

\subsection{Sarawak Peat}

The peat samples are taken from Kpg. Endap, Kota Samarahan (later known as Sarawak peat) between 0.25 to $1.50 \mathrm{~m}$ depth below the ground surface. Table 1 presents the basic geotechnical properties of Sarawak peat. The Von Post classification test was performed, and almost all the peat escaped between the fingers upon squeezing and only a small quantity of decomposed plant remained in the hand (Fig. 1). Thus, the peat is categorized as Sapric peat, H7 (highly decomposed), with dark brown in colour. The organic content of Sarawak peat is best determined by performing the loss of ignition test. From the test, one can be seen that the organic content of Sarawak peat is very high, which varies from $88 \%$ to $95 \%$. Further, higher percentage of organic matter produced relatively high moisture content of Sarawak peat ranges from $480 \%$ to $606 \%$. Based on the published work, it has been proven indeed reasonable that the voids between organic particles have a high capacity of entrapping moisture content, which resulted in high moisture content of peat. From the finding, it is clearly shown that, the organic content does affect the moisture content of Sarawak peat. The $\mathrm{pH}$ value for Sarawak peat falls in the range of 3.0 to 4.0, to which are classified as highly acidic (ASTM D2976).

\subsection{Tire-Waste Disposal: Shredded Rubber-Crumb and Fiber-Polyester}

Shredded rubber-crumb and fiber-polyester (Fig. 2) used in this study as reinforcement material is supplied by ZHA Environmental Sdn. Bhd. (ZHA). The ZHA recycle the collected disposal tire and adopts a mechanical grinding process with different physical characteristic such as size and shape alteration and the reinforcing wire and fiber-polyester from the tire are removed before converting into rubber-crumbs, powder and fiber-polyester. The size of the shredded rubber-crumb and fiber-polyester used in this study is an approximately $5-8 \mathrm{~mm}$ and $10.0-12.5 \mathrm{~mm}$, respectively.

The specific gravity, Gs, 1.47 for the shredded rubber-crumb and 1.07 for fiber-polyester are recorded in this study. Both materials show lower specific gravity, which indicate as a lightweight type material.

Table 1: Physical properties of Sarawak peat

\begin{tabular}{|c|c|}
\hline Physical Properties & Values \\
\hline Von Post Classification & H7 (Sapric) \\
\hline Moisture Content $\left(w_{N}\right)(\%)$ & $480-606$ \\
\hline Liquid Limit, LL (\%) & $\begin{array}{c}\text { Natural state: } 416 \\
\text { Dried state: } 106-132\end{array}$ \\
\hline
\end{tabular}

\begin{tabular}{lc}
\hline Shrinkage Limit, SL $(\%)$ & Dried state: 9.29 \\
\hline Organic Content, OC $(\%)$ & $88-95$ \\
\hline Fiber Content, FC $(\%)$ & 21.9 \\
\hline $\mathrm{pH}$ Value & $3-4$ \\
\hline Specific Gravity $\left(G_{s}\right)$ & $1.54-1.59$ \\
\hline
\end{tabular}

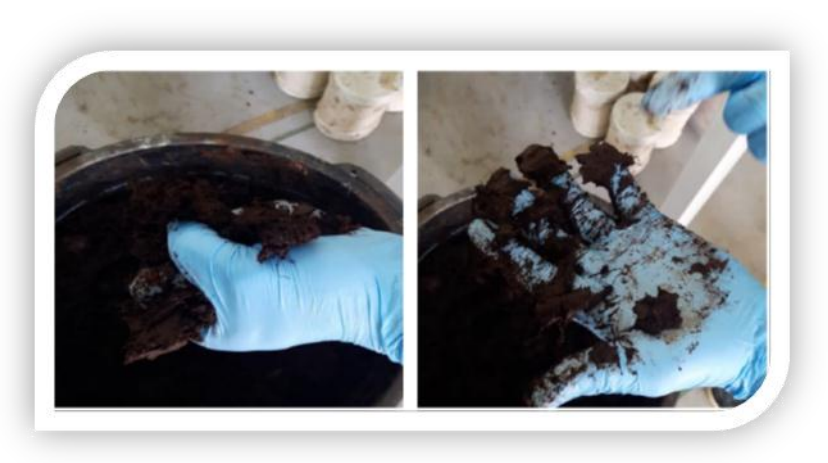

Fig. 1: Von Post scale classification - Sapric peat $(\mathrm{H} 7)$
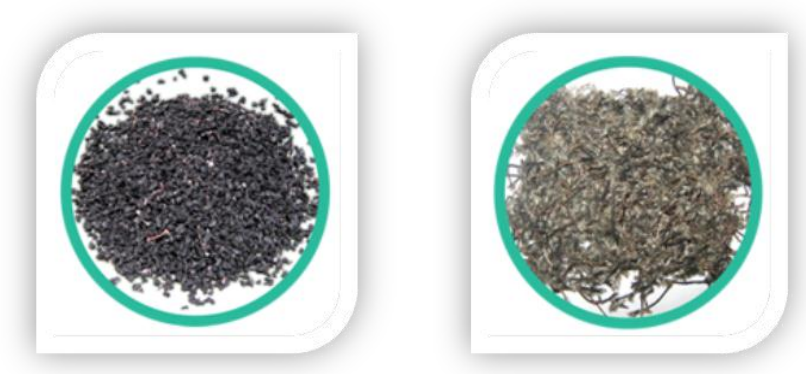

Fig. 2: Processed tire-waste disposal: (a) Shredded rubber-crumb and (b) Fiber-polyester

\section{Methods - Experimental Programme}

A series of laboratory tests was conducted on the collected peat, which reinforced with various percentages of the shredded rubbercrumb (RC), fiber-polyester (FP) and 5\% cement (C) content. The cement acts as the binding agent and the shredded rubber-crumb and fiber-polyester act as non-active agent. The tests performed include Proctor compaction test, unconfined compressive strength (UCS) test and California bearing ratio (CBR) test. Table 2 presents a summary of the design mix of the reinforced peat samples by varying the proportion of the shredded rubber-crumb and fiberpolyester. The percentages used of RC were $5 \%, 10 \%$ and $15 \%$ and of FP were $0.25 \%, 0.50 \%$ and $0.75 \%$ of the total mass of dryweight of the mixture without and with $5 \%$ of cement content.

The collected peat samples are first dried under direct sunlight, crushed down by machine and sieving to a size finer than $2 \mathrm{~mm}$ sieve. Then, the mixture of peat with various percentages of RC and FP is homogeneously mixing using laboratory mixer for at least 3 mins after the addition of water (intended moisture content) to ensure all the reinforced materials were effectively distributed with the soil matrix. All the specimens were prepared to the optimum moisture content and maximum dry density (MDD). The designated amount of cement was then added to the mix for preparation of samples. The samples were then wrapped with thin plastic film and stored in the humidity control chamber until testing at 7 and 28 days of curing period (single batch mixing). In this study, peat and peat-cement mix were also prepared and acts as the control samples. This reinforcement technique using lightweight material is believed to increase the cohesion among the soil particles and makes them behave as a structural mesh that holds the soil together to increase the soil structural integrity. 
Table 2: Design mix of various percentages for shredded rubber-crumb (RC) and fiber-polyester (FP)

\begin{tabular}{ccc}
$\begin{array}{c}\text { Design } \\
\text { mix }\end{array}$ & $\begin{array}{c}\text { Shredded Rubber- } \\
\text { Crumb }\end{array}$ & Fiber-Polyester \\
\hline 1 & \multicolumn{1}{c}{ Peat (Unreinforced peat) } \\
\hline 2 & \multicolumn{2}{c}{ Peat $+5 \%$ C } \\
\hline 3 & Peat $+5 \%$ RC & Peat $+0.25 \%$ FP \\
& Peat $+10 \%$ RC & Peat $+0.50 \%$ FP \\
& Peat $+15 \%$ RC & Peat $+0.75 \%$ FP \\
\hline 4 & Peat $+5 \% \mathrm{C}+5 \%$ RC & Peat $+5 \% \mathrm{C}+0.25 \%$ FP \\
& Peat $+5 \% \mathrm{C}+10 \%$ RC & Peat $+5 \% \mathrm{C}+0.50 \%$ FP \\
& Peat $+5 \% \mathrm{C}+15 \%$ RC & Peat $+5 \% \mathrm{C}+0.75 \%$ FP \\
\hline
\end{tabular}

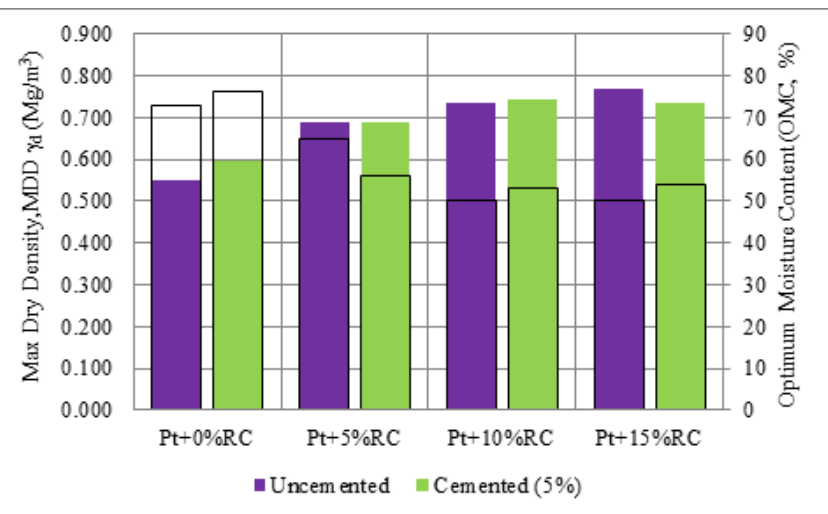

Fig. 3: MDD-OMC of uncemented \& cemented reinforced peat with shredded rubber-crumb (RC)

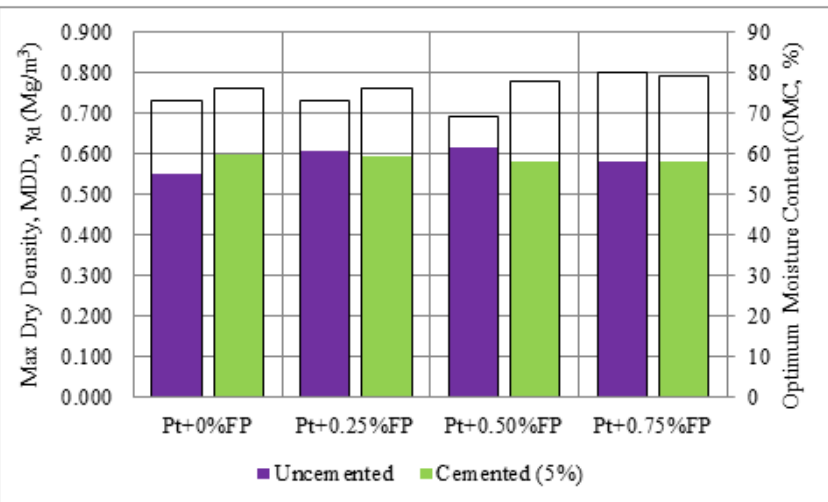

Fig. 4 :MDD-OMC of uncemented \& cemented reinforced peat with fiberpolyester (FP)

\section{Results and Discussion}

The results on the effect of the reinforced peat using shredded rubber-crumb (RC) and fiber-polyester (FP) by performing the Proctor compaction test, unconfined compressive strength tests and California bearing ratio tests are presented in the following section.

\subsection{Proctor Compaction Test - Effect of Maximum Dry Density (MDD) - Optimum Moisture Content (OMC) between Unreinforced, Uncemented and Cemented Re- inforced Peat}

The compaction tests were performed to determine moisturedensity relationship of unreinforced peat, uncemented and cemented reinforced peat (with the inclusion of shredded rubbercrumb (RC) and fiber-polyester (FP) (without cement and then with cement). This test was conducted in accordance to BS: 1377: Part 4: 1990 where the soil is compacted in 3 layers with 25 blows for each layer using $2.5 \mathrm{~kg}$ weight of the hammer.

The results of maximum dry density (MDD) of all design mixture for unreinforced peat, uncemented and cemented reinforced peat are illustrated in Fig. 3 and Fig.4, respectively. One can be seen that, with an increasing percentage of shredded rubber-crumb for uncemented and cemented reinforced peat, the maximum dry density increased by significantly decreasing the optimum moisture content. This behavior may due to the higher water absorption of the shredded rubber-crumb. While, for the fiber-polyester, the opposite behavior was observed and this may due to the fiberpolyester having low specific gravity and have a greater water holding capacity than peat. The addition of cement into the peat can be attributed to absorption of water development of hydration and bring changes in base exchange, aggregation and flocculation, resulting in an increased void ratio of the mix leading to a decrease in the density of the mix [7].

\subsection{Unconfined Compressive Strength (UCS) Test - Effect of Compressive Strength between Unreinforced, Uncemented and Cemented Reinforced Peat}

The unconfined compressive strength test was conducted in accordance with BS 1377: Part 7: 1990, which defined as load per unit area, where the soil will fail in the axial compression test. A total of 64 reinforced peat samples were compacted at the optimum moisture content using Harvard Miniature Compactor on cylindrical specimens with $38 \mathrm{~mm}$ diameter and $76 \mathrm{~mm}$ high size for curing period of 7 and 28 days. Two specimens of each design mix of samples were tested, and the average of the two results was recorded as the UCS values for the particular sample types.

The results of the unconfined compressive strength were plotted in Fig. 5 to Fig. 8. It is observed that the UCS value of the uncemented and cemented reinforced peat increases with the inclusion of shredded rubber-crumb and fiber-polyester up to $5 \%$ $\mathrm{RC}$ and $0.25 \% \mathrm{FP}$, respectively. Then it decreases with the further inclusion of RC and FP beyond the stated values. However, from the observation, even though the strength is decreasing, higher shredded rubber-crumb and fiber-polyester content appears to have a smaller crack length of the specimen. This can be further explained, increasing the reinforced materials content causes the interface between the reinforced materials and soil particles increase and hence the friction increase, which renders it difficult for soil particles that surround the reinforced materials to change in position from one point to another and thereby improves the bonding force between soil particles, i.e., cohesion of the soil. Moreover, when local cracks appear in the soil, reinforced materials across the cracks will take on the tension in the soil, which effectively impedes further development of cracks and improves the resistance of the soil to the force applied [7]. It is also noted by [8] that the ability of the fibers to prevent further cracks as bridge effect of the fiber inclusion.

The effect of curing period on the UCS samples shows that the strength increased as the curing period increased. Further, the addition of $5 \%$ cement into the reinforced peat shows an increment in the strength after 28 days curing with values of $55 \mathrm{kPa}$ for $\mathrm{RC}$ and $221 \mathrm{kPa}$ for FP, respectively. This indicates that there is a perfect adhere between the reinforced peat and cement matrix. Further, it can be explained that the total contact area between the reinforced materials and peat particles increases, and consequently the friction between them increases, which contributes to the increase in resistance to forces applied. This behavior was also observed by [7] and [9]. 


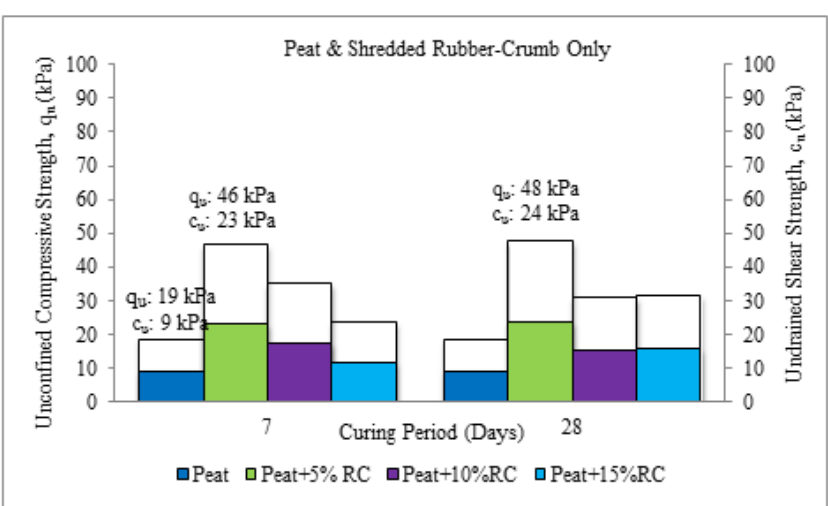

Fig. 5: Peat and uncemented reinforced peat with shredded rubber-crumb

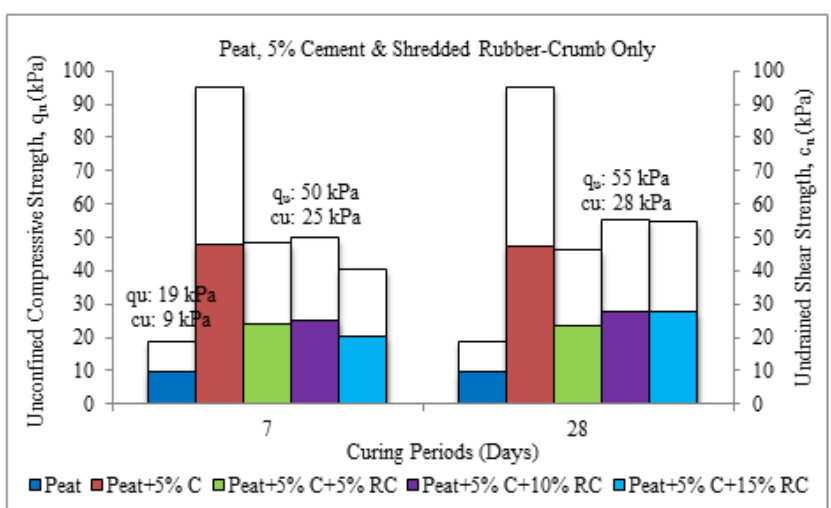

Fig. 6: Peat and cemented reinforced peat with shredded rubber-crumb

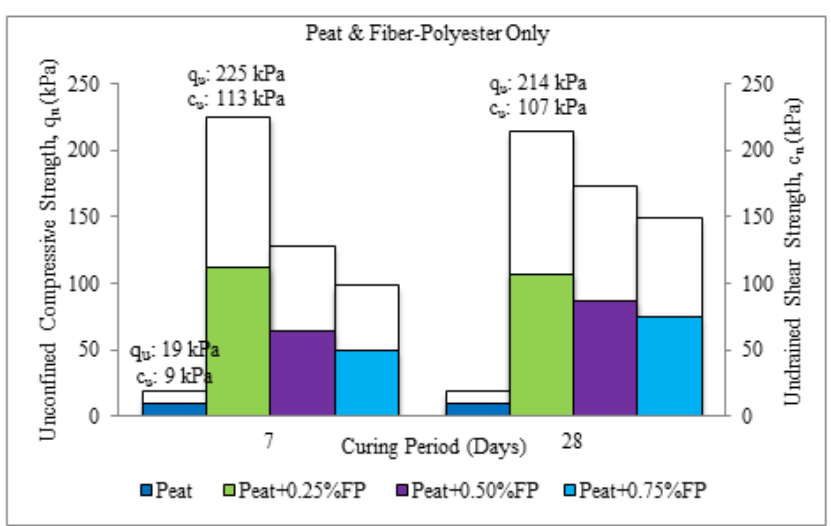

Fig. 7: Peat and uncemented reinforced peat with fiber-polyester

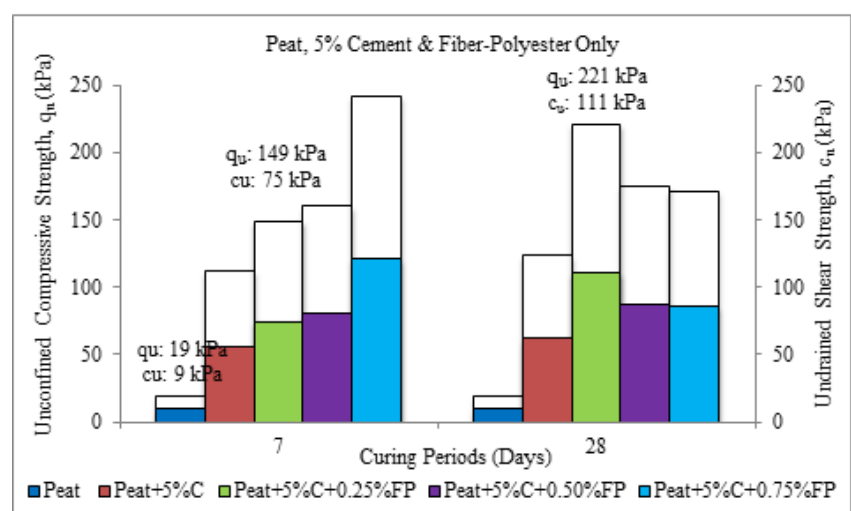

Fig. 8: Peat and cemented reinforced peat with fiber-polyester

Fig. 9 shows the photograph of the change in the microstructure between uncemented and cemented peat by using scanning electron microscopy (SEM). The specimens were taken after conducting the UCS tests at 28 days. From the photograph presented, the uncemented peat (Fig.9 (a)) has large pores, which can hold a considerable amount of moisture content in their structures and resulted high initial void ratio. Further, it can be clearly observed that there is considerable reduction in pore spaces in cemented peat when compared with uncemented peat. The reduction in pore space is mainly due to the crystalline growth resulted from the hydration process. Besides that, it is found that the crystalline growth is enhanced with the addition of cement in the mixture. The SEM analyses are performed only for uncemented and cemented peat at curing period of 28 days. Other specimens are not able to proceed due to some technical errors occurred during the scanning.

(a)

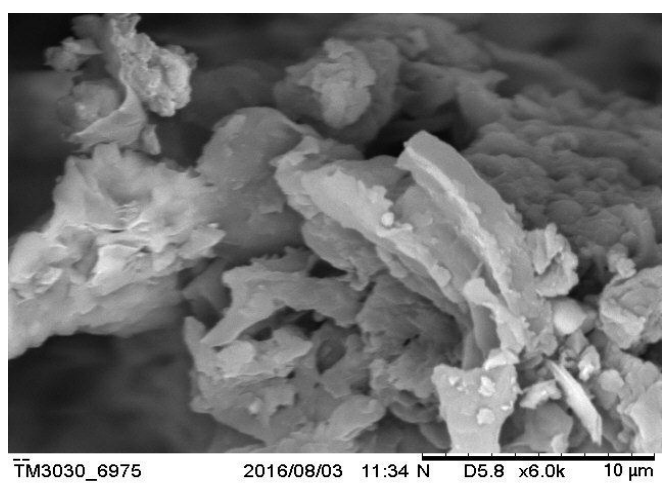

(b)

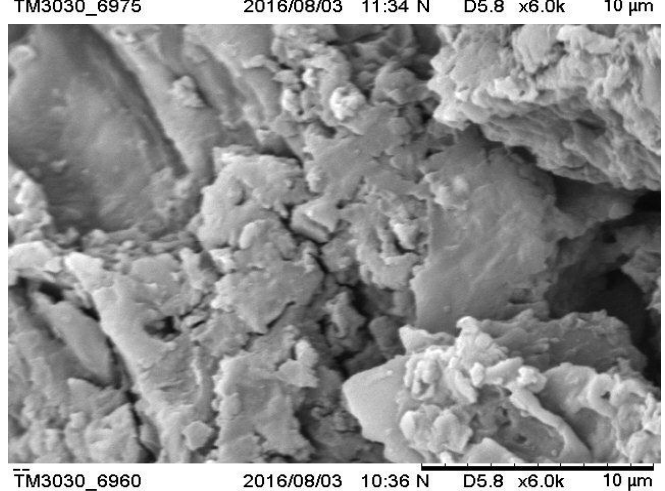

Fig. 9: SEM image (a) Uncemented peat at 28 days X40 (b) Cemented peat at 28 days X40

\subsection{California Bearing Ratio (CBR) Test - Effect of Strength between Unreinforced, Uncemented and Ce- mented Reinforced Peat}

CBR test is used to evaluate the effects of adding the reinforced materials on the strength of reinforced peat for sub-grade. In this study, the CBR tests are conducted for both unreinforced and reinforced peat at the same MDD and OMC for maintaining uniformity. The CBR tests were conducted inside a modified proctor mould at soaked condition. The mould was a rigid metal cylinder with an inside diameter of $152 \mathrm{~mm}$ and a height of $178 \mathrm{~mm}$. A calibrated load indicating device was used to force the penetration piston with a diameter of $50 \mathrm{~mm}$ into the specimen. The loads were carefully recorded as a function of penetration up to a total penetration of $50 \mathrm{~mm}$ to observe the post-failure behavior as well. In this section, only the results of unreinforced and reinforced peat using shredded rubber-crumb on the soaked CBR are presented. Fig. 10 illustrated the effect of inclusion of shredded rubber-crumb into peat.

The soaked CBR value for unreinforced peat is $0.75 \%$. A sharp increment in CBR value of for the inclusion of $5 \%$ shredded rubber-crumb was observed. However, further inclusion of shredded rubber-crumb content of $10 \%$ and $15 \%$ decrease the soaked value. This is because further increment of rubber crumb into peat samples reduced its resistance to deformation under applied load. Therefore, the frictional resistance between peat and reinforced material (shredded rubber-crumb) increase as the amount increase. At the optimum amount of shredded rubber-crumb inclusion $(5 \%)$, the percentage of CBR value increased when compared with the natural state of peat. The reinforced peat has good inter- 
locking resistance to the applied load and reduced the mobilization between particles. The higher amount of fiber reinforced material decreases the density of the stabilized peat thus attributes to the lack of frictional resistance between peat and reinforced peat with shredded rubber-crumb. According to JKR Malaysia Design Manuals [10], the minimum sub-grade must have CBR value of $5 \%$. Thus, this indicates that the reinforced peat using shredded rubbercrumb presented in this study has improved the strength of the peat sub-grade.

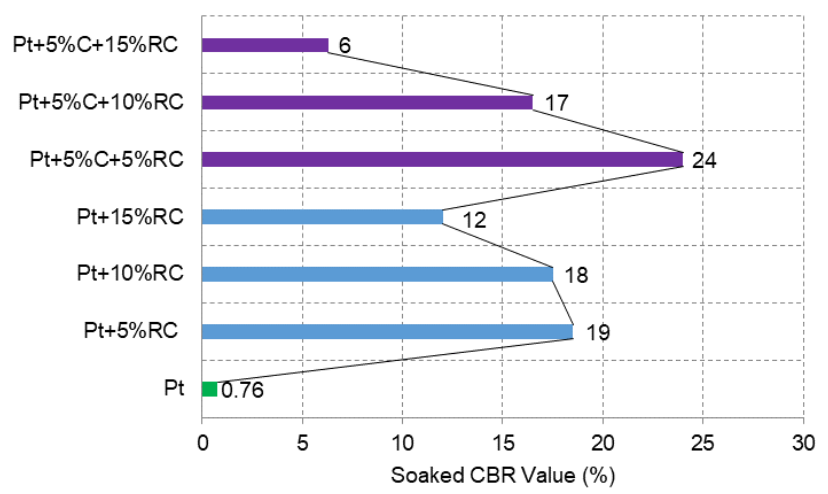

Fig. 10: Effect of inclusion of shredded rubber-crumb on soaked CBR value

\section{Conclusion}

A series of unconfined compressive strength tests and California bearing ratio tests were conducted on the reinforced peat using lightweight waste material; shredded rubber-crumb and fiberpolyester (a product of tire-waste disposal). From the study, it can be observed that the strength improvement for both the uncemented and cemented reinforced peat from UCS tests shows an increment with the inclusion of shredded rubber-crumb and fiberpolyester up to $5 \% \mathrm{RC}$ and $0.25 \% \mathrm{FP}$, respectively. Then it decreases with the further inclusion of RC and FP. The maximum strength gain is $55 \mathrm{kPa}$ for $\mathrm{RC}$ and $221 \mathrm{kPa}$ for $\mathrm{FP}$ are recorded. The CBR value of the reinforced peat increases for all design mix when compared with the natural peat and the highest CBR value recorded is $5 \%$ shredded rubber-crumb. In conclusion the addition of reinforced materials of shredded rubber-crumb and fiberpolyester can improve the engineering properties of peat and these results were useful in the selection of the optimum percentage of design mix based on the purpose of the construction involved.

\section{Acknowledgement}

The study was funded by Special Short-Term Grant Scheme (SpSTG-F02/SpSTG/1377/16/19), Universiti Malaysia Sarawak (UNIMAS). The first author would like to thank ZHA Environmental Sdn. Bhd for providing the fiber-polyester and shredded rubber-crumb, a product from processed tire-waste disposal. Also, special thanks to all research team members for their assistance and dedication, especially to Doreen Bong, Jacqueline Awang and Athirah Bakie. The technical staff of Geotechnical Laboratory, UNIMAS for helping in collecting the peat samples and resources provided. Finally, to those who are contributing directly and indirectly towards the fiber-reinforced techniques study of Sarawak peat.

\section{References}

[1] Edil TB (2003), Recent advances in geotechnical characterization and construction over peats and organic soils. 2nd International Conference on Advances in Soft Soil Engineering and Technology, 2 - 4 July 2003, Putrajaya, Malaysia.
[2] Singh H and Huat BBK (2003), Tropical peat and its geotechnics. 2nd International Conference on Advances in Soft Soil Engineering and Technology, 2 - 4 July 2003, Putrajaya, Malaysia.

[3] Tai LY, Lee KW, Ting WH (2003), Some interesting aspects of peat formations in Sibu Town and related engineering issues. 2nd International Conference on Advances in Soft Soil Engineering and Technology, 2 - 4 July 2003, Putrajaya, Malaysia.

[4] Huat BBK and Bahia HM (editors) (1997), Proceedings of International Conference on Recent Advances in Soft Soil Engineering. pp.510.

[5] Huat BBK, Asadi A, Kazemian S (2009), Experimental investigation on geomechanical properties of tropical organic soils and peat. American Journal of Engineering and Applied Sciences 2(1), 184188.

[6] Maheshwari K, Solanki CH, Desai AK (2013), Effect of polyester fibers on strength properties of clayey Soil of high plasticity. International Journal of Scientific \& Engineering Research 4(6), 486491.

[7] Kumar A, Gupta D (2016), Behavior of cement-stabilzed fiberreinforced pond ash, rice husk ash-soil mixtures. Geotextiles and Geomembranes 44, 466-474.

[8] Tang CS, Shi B, Gao W, Chen FJ, and Cai Y (2007), Strength and mechanical behavior of short polypropylene fiber reinforced and cement stabilized clayey soil. Geotextile and Geomembrane 25(3), 194-202.

[9] Cai Y, Shi B, Ng CWW, Tang CS (2006), Effect of polypropylene fibre and lime admixture on engineering properties of clayey soil. Engineering Geology 87(3), 230-240.

[10] JKR Malaysia (1985), Manual on Pavement Design, Arahan Teknik (Jalan) 5/85. Jabatan Kerja Raya Malaysia. 